\section{Ovary Sealing Colonoscopic Perforation}

Colonoscopic perforations occur in less than $1 \%$ of patients undergoing colonoscopy and may be seen in up to $3 \%$ of those undergoing therapeutic procedures [1].

A 70-year-old woman presented with persistent abdominal pain, nausea, weakness and fatigue of 16 days' duration. Immediately preceding the onset of symptoms, she had undergone diagnostic colonoscopy for evaluation of occult blood in her stool; a $2.0-\mathrm{cm}$ sessile polyp had been identified in the sigmoid colon but polypectomy had not been believed to be safe. On admission, abdominal examination was remarkable only for moderate tenderness in the left lower quadrant. An abdominal radiograph demonstrated free air below the right hemidiaphragm. The patient was successfully treated conservatively with total parenteral nutrition and antibiotics. Histological findings from the subsequently biopsied polyp demonstrated well-differentiated adenocarcinoma in tubular adenoma. At surgery, a $10-\mathrm{cm}$ segment of the redundant sigmoid proximal to and remote from the site of the polyp appeared markedly edematous, rigid, and inflamed. It was situated in the pelvis, and the left ovary

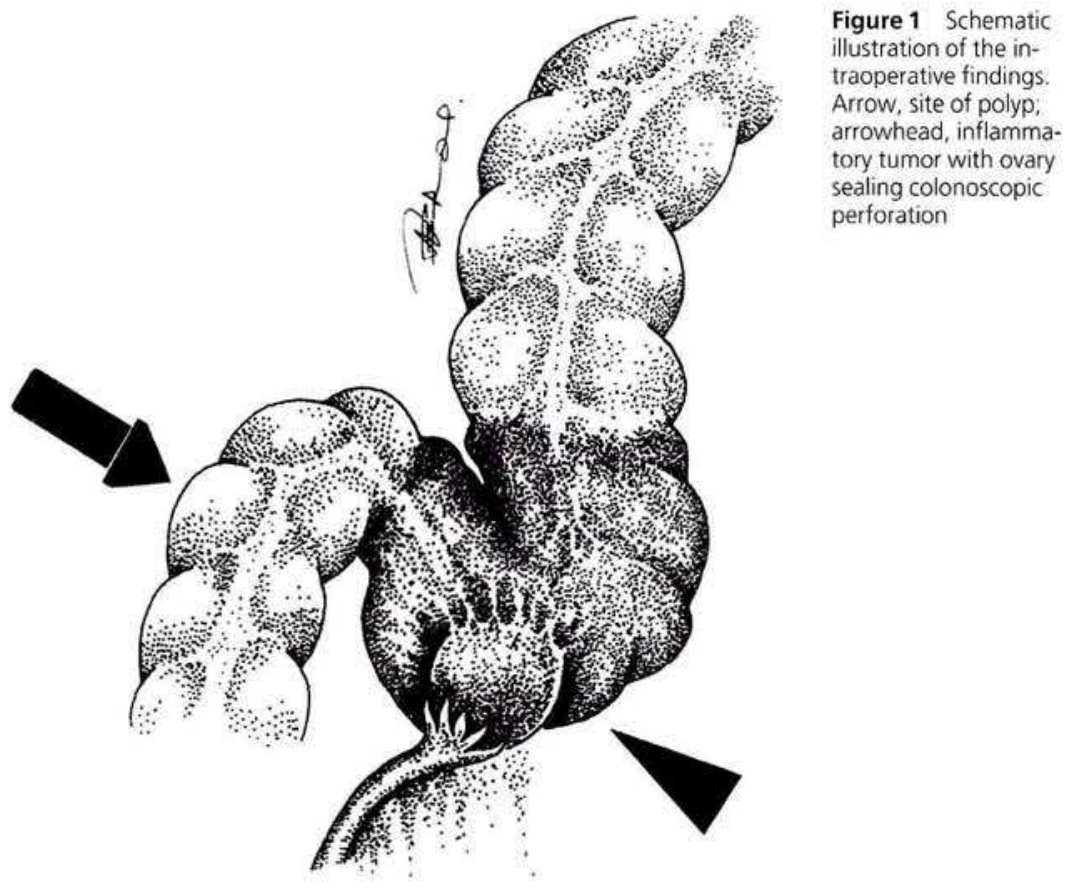

which was also severely inflamed, was found adherent to the antimesenteric aspect of bowel (Figure 1). After the ovary was lifted off, an underlying $0.4-\mathrm{cm}$ perforation was noted. Left hemicolectomy with anas- tomosis, along with left adnexectomy was carried out, and the patient's postoperative course was unremarkable. 
In this case, sealing of the perforation by the ovary conferred an advantage to the patient, allowing a planned operation in a well-controlled environment to be carried out [2,3]. Our observation seems to prove that this might be effective, even with a 16-day delay in diagnosis! It seems that, similar to the vermiform appendix in exceptional circumstances [4], the ovary may be regarded as a "policeman of the abdomen."

\section{J. E. Losanoff', K. T. Kjossev²}

' Dept. of Emergency Surgery,

Military Medical Academy,

Sofia, Bulgaria
${ }^{2}$ Dept. of General Surgery, Military Medical Academy, Sofia, Bulgaria

\section{References}

1. Damore LJ, Rantis PC, Vernava AM, Longo WE. Colonoscopic perforations: etiology, diagnosis, and management. Dis Colon Rectum 1996; 39: 1308-14

2. Seow-Choen F, Look MCM, Ho YH. Non-surgical management of colonoscopic bowel perforation. Int J Colorectal Dis 1995; 10: 77-8

3. Lo AY, Beaton HL. Selective management of colonoscopic perforations. J Am Coll Surg 1994; 179: 333-7
4. Adachi $\mathrm{Y}$, Murakami N, Matsumata T. Vermiform appendix sealing sigmoid colon perforation. J Clin Gastroenterol 1996; 23: 164

Corresponding Author

J. E. Losanoff, M.D.

PO Box 159

1606 Sofia

Bulgaria

Fax: +359 (2) 560835

E-mail: freckles@public.digsys.bg 